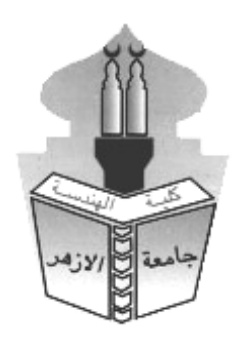

\title{
NANOTECHNOLOGY: TOWARDS THE SUSTAINABILITY OF CONTEMPORARY ARCHITECTURE
}

\author{
*Rania Said Sayd Mourad ${ }^{1}$, Mohamed Zakria El-Dars ${ }^{2}$ and Alaa-aldien Alsaied Farid ${ }^{2}$ \\ 1 Architect, Development, Research \& Studies, Dep. Fund, Ministry of Housing, Cairo, Egypt \\ ${ }^{2}$ Department of Architecture, Faculty of Engineering, Al-Azhar University, Cairo, Egypt \\ *Corresponding author E-mail: architecture_rania@hotmail.com
}

\begin{abstract}
The research discussed concept of nanotechnology, which is concerned with studying and rearranging the properties of materials up to $100 \mathrm{~nm}$ in order to reach new materials that have a new characteristics and functions superior to traditional materials. The Nano material are characterized by new properties and behaviors, because these materials exhibit new physical and chemical concepts due to their composition. The research discussed the impact of Nano technology on architecture, where Nano materials provided creative design to form of the building, as well as the distinctive characteristics of Nano materials in form and functionalities, which increases the efficiency of the performance of the building internally and externally. The research also discussed the concept of sustainable Nano architecture, which is the integration of Nano architecture with sustainability, in order to achieve the sustainability of buildings with modern technological tools. study also discussed architectural trends aim to achieve sustainable Nano architecture, such as (biological Nano architecture, ecological Nano architecture, and smart Nano architecture) with example studying demonstrating its trends and how it achieves sustainability.
\end{abstract}

Key words : Nanotechnology, Bio Nano architecture, Ecological Nano architecture, Smart Nano architecture, Photo catalysis.

$$
\begin{aligned}
& \text { تكنولوجيا النانو : نحو استدامة معمارية معاصرة }
\end{aligned}
$$

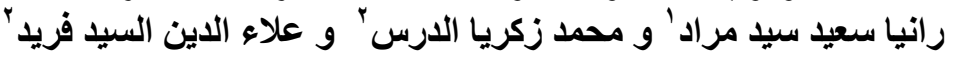

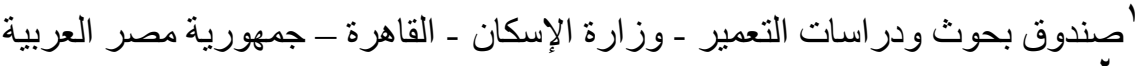

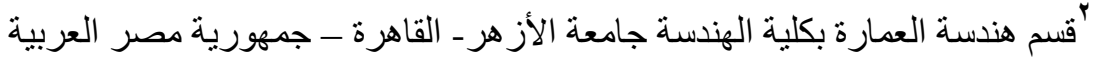

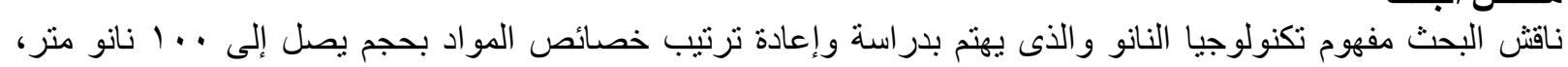

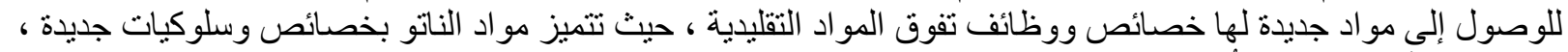

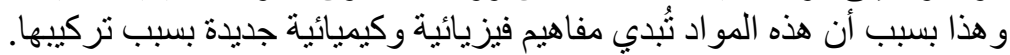

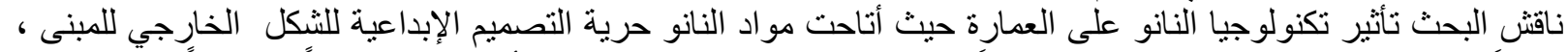

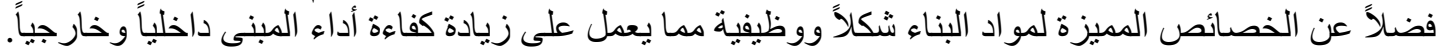

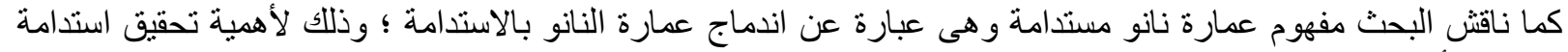

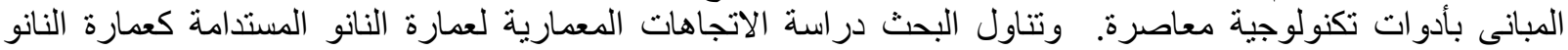

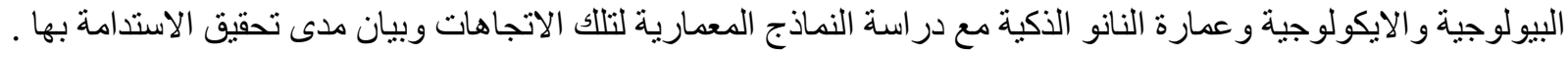

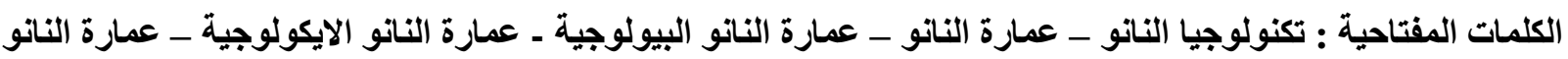

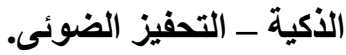




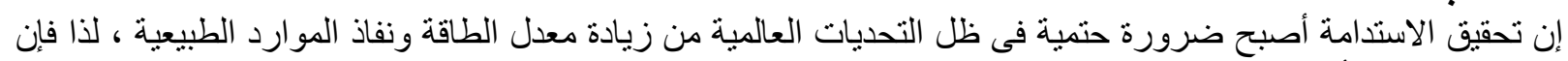

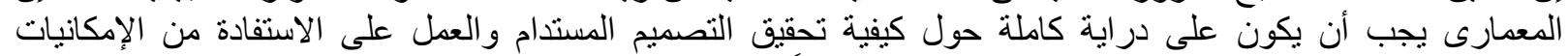

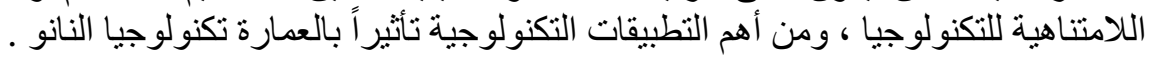

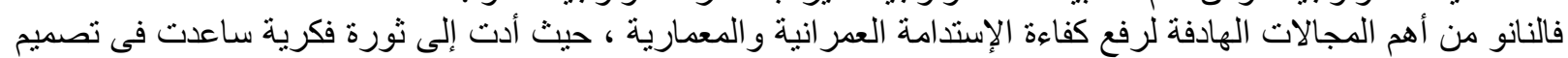

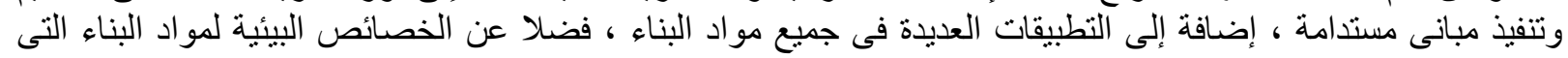

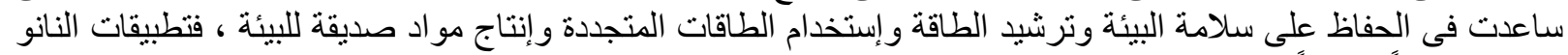

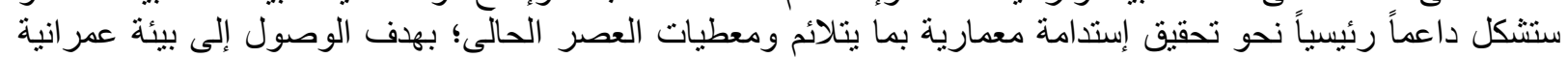

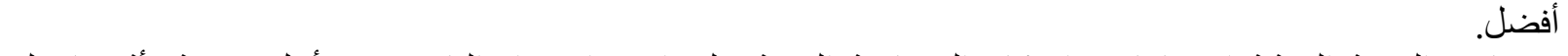
وستناقش الورقة البحثية الإتجاهات والافكار المعمارية المبنية على إستخدام مواد النانو ؛ من أجل معرفة نأثيرها على إستدامة المبانى من أجل بيئة عمر الإنية أفضل.

المشكلة البحثية المثنة

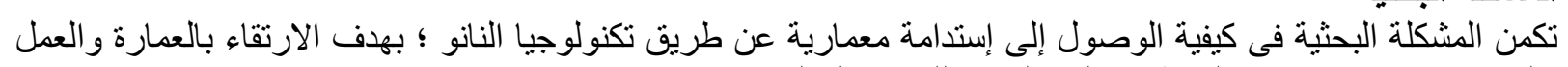

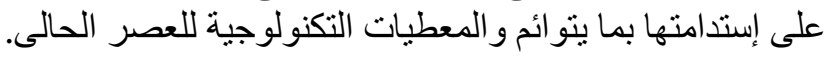

الفرضية العلمية تكنولوجيا النانو داعمة للاستدامة المعمارية بشكل مبتكر وبأدوات تلتلائم ومعطيات التكنولوجيا الحديثة وستشكل إطار متكامل لإستدامة المبانى من أجل بيئة عمر انية أفضل.

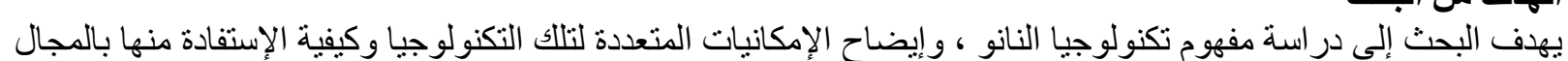

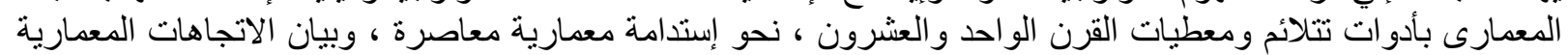

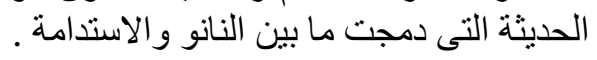

ا ـ أكنولوجيا النانو:

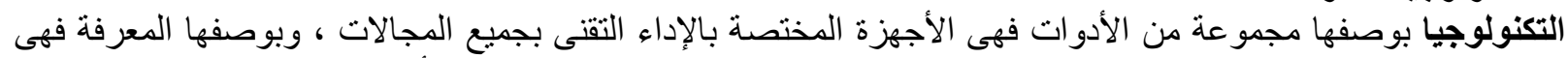

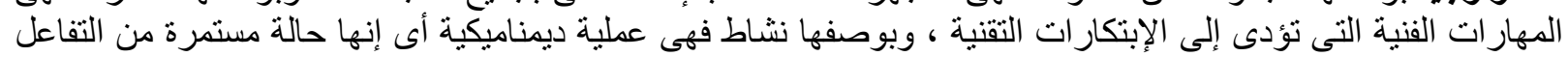

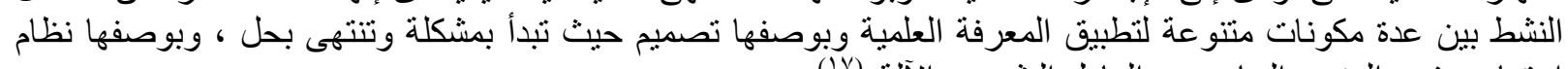

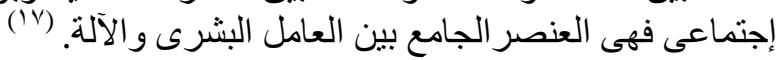

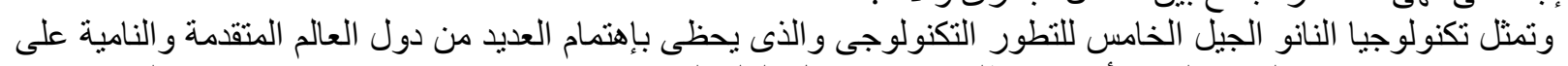

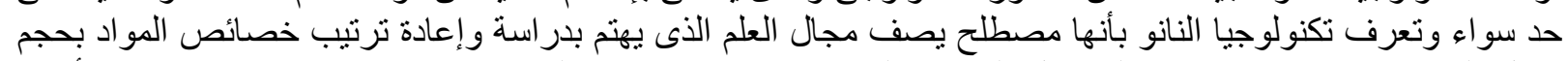

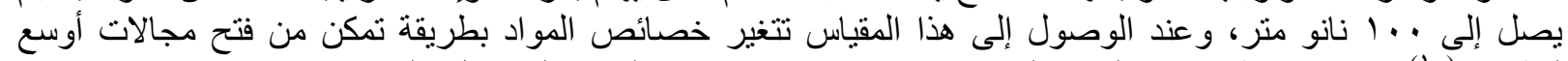

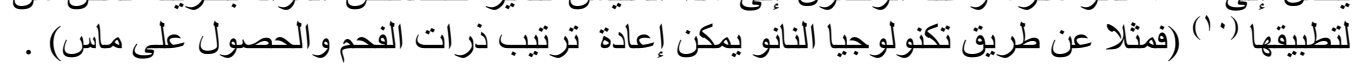

r. التطور التاريخى لتكنولوجيا النانو:

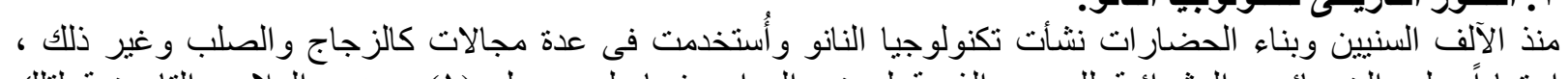

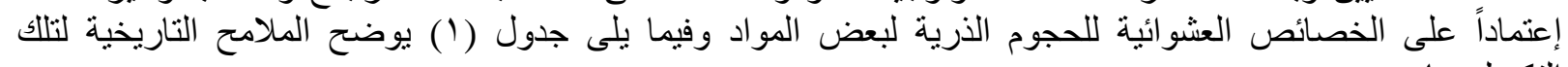
التكنولوجيا . 
إستذام حبيبات ذهب النانو فى تلوين الزجاج ، مثل كاس الملك الرومانى لايكورجوس والموجود بالمتحف البريطانى.

السيف الدمثقي المعروف بصلابته و المصنوع من أنابيب بأبعاد نانومترية من الكربون، أعطت هذا السيف ميزاته الفائقة.

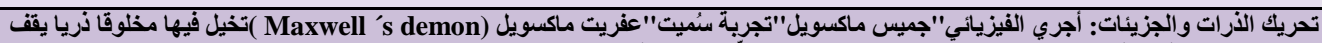

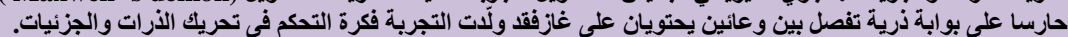

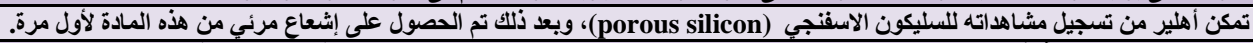

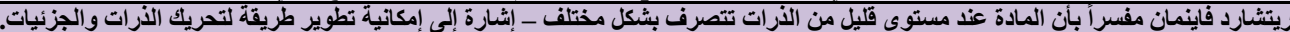

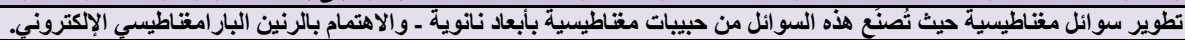

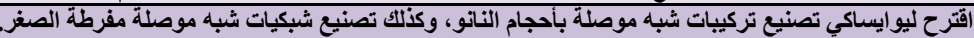

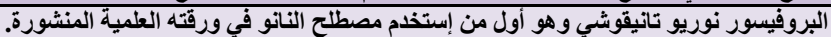

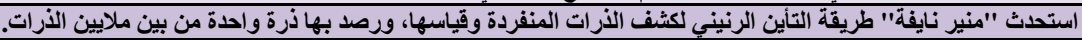
+ $19 \vee \varepsilon$

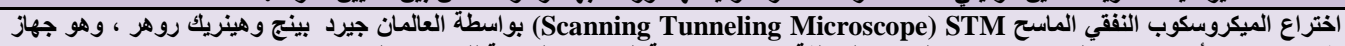

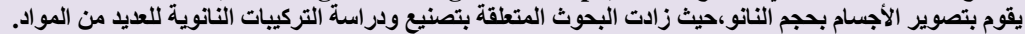

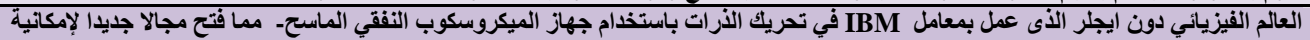

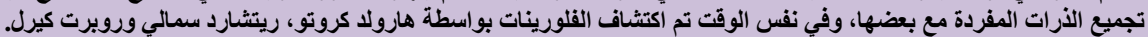

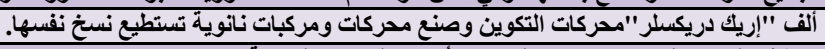

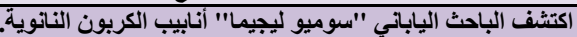

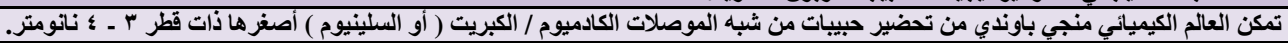

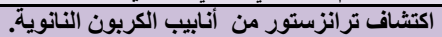

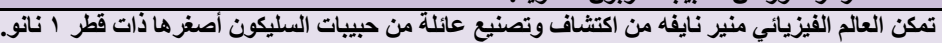

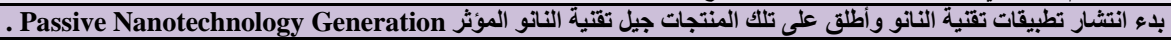

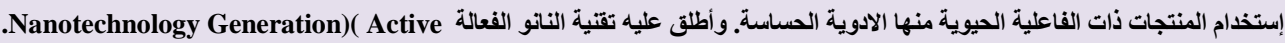

إستخدام الروبوت الطبي المتقدم- وأُطلق على الإجزةة جيل أنظمة النانو(Systems of nanotechnology Generation).

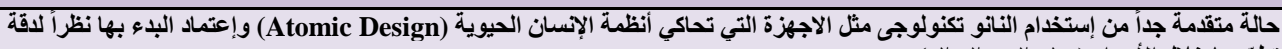

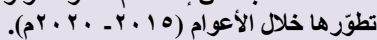




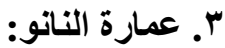

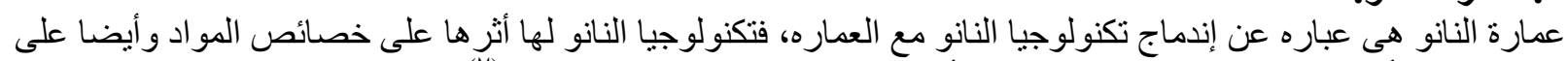

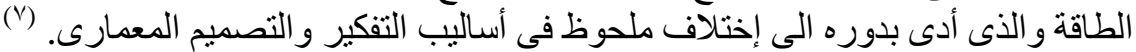

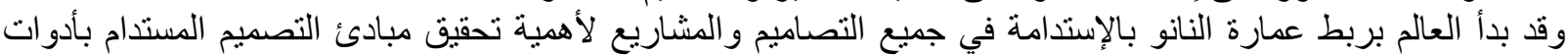

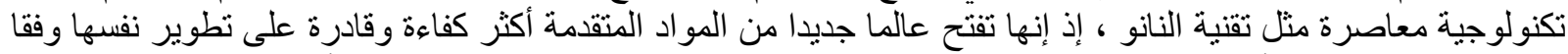

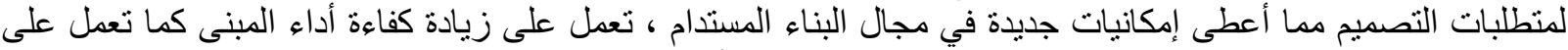

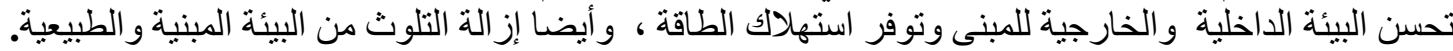

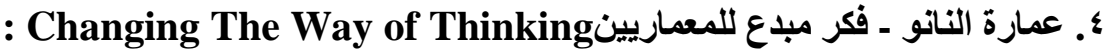

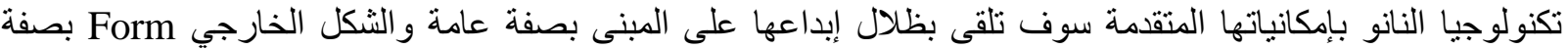

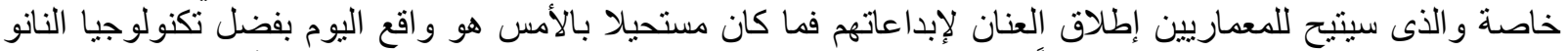

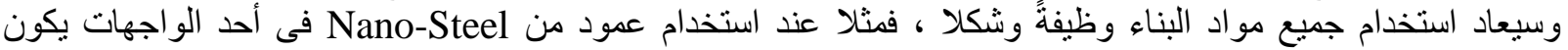

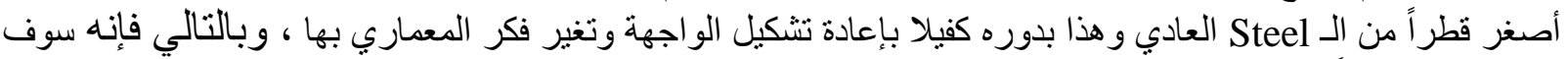
يتغير المبنى شكلاً ووظيفية.

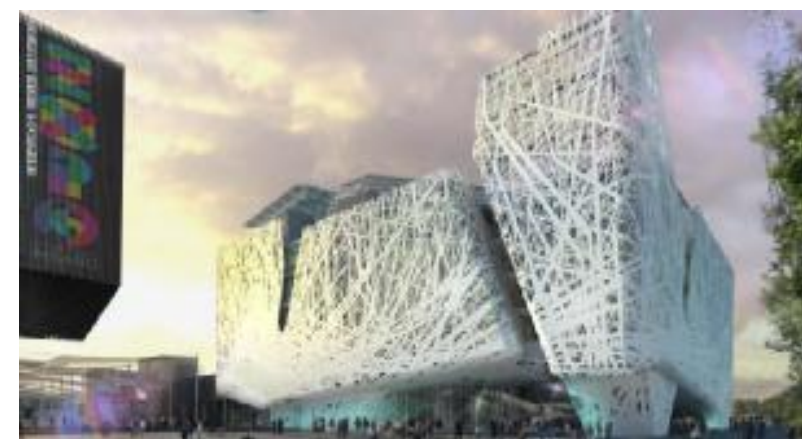

شكل (1) واجهة مبنى Palazzo Italia المرجع : (r)

تقنية النانو اتاحت تغير الفكر المعماري بكل أنشكاله فأصبح

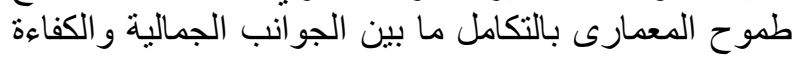

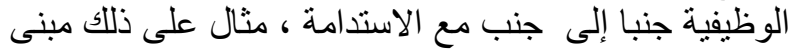
مكافح للتلوث "Palazzo Italia" "بميلانو - إيطاليا حيث الابث

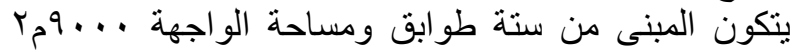

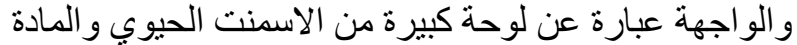

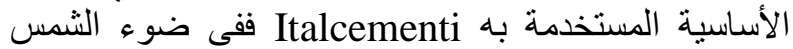
المبانشر تتشط هذه المادة وتحول الملونات المات بالهو اء إلى أملاح

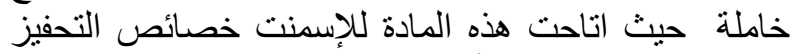

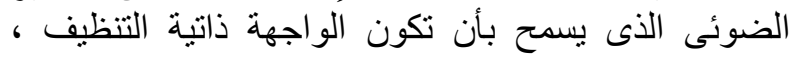
ويوضح شكل (1) ش شكل الو اجهة.

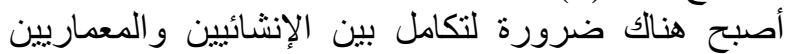

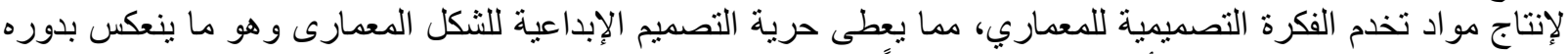
على التتكيل الخارجي للمبنى الأمر الذى يؤثر إيجابياً على التشكيل الداخلى للفر اغات المعمارية وبالتنالي العلاقات الوظيفية

فيما بينها.

0. - ممارة النانو المستدامة.

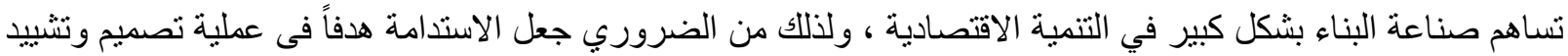

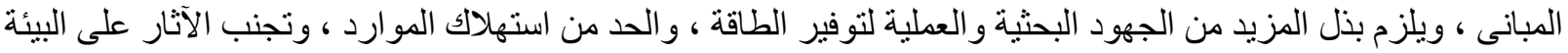

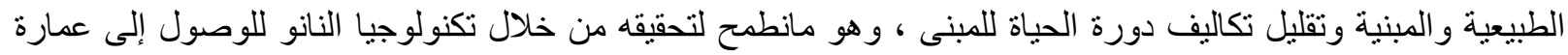
النانو المستدامة . Sustainable Nano Architecture (SNA). من أجل بيئة عمر انية منوازنة ، ويوضح شكل (Y) أهم الاتجاهات والأفكار المعمارية المبنية على استخدام مو اد النانو بطريقة مستدامة

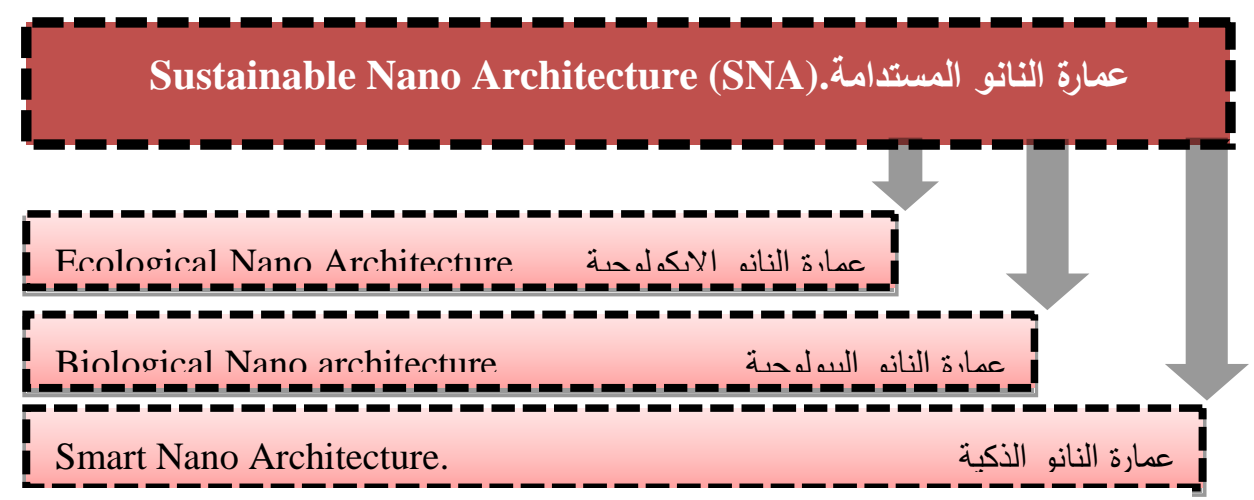

شكل (ץ) اتجاهات عمارة النانو المستدامة المرجع:( (1) 
وسيناقش البحث بالتفصيل تلك الاتجاهات كما يلى:

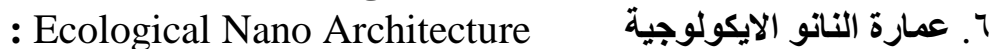

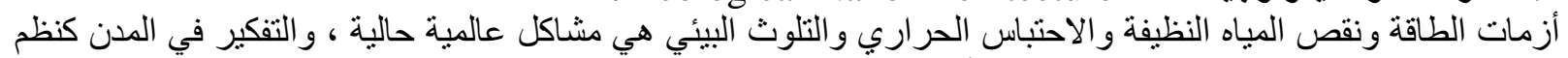

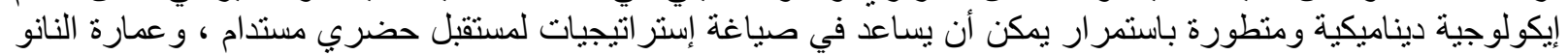

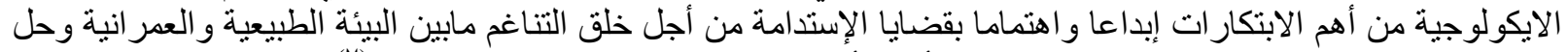

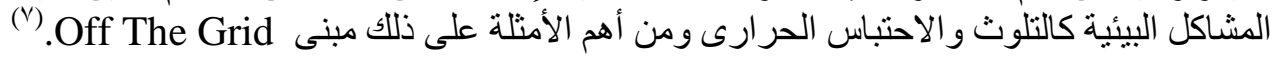

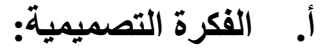

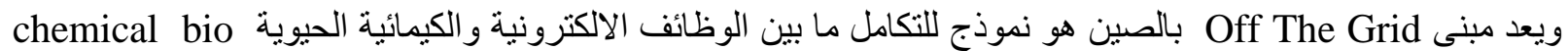

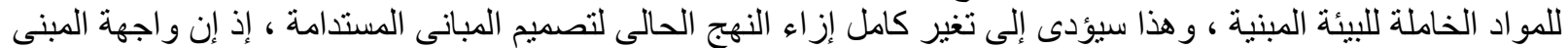

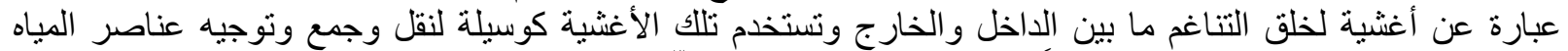

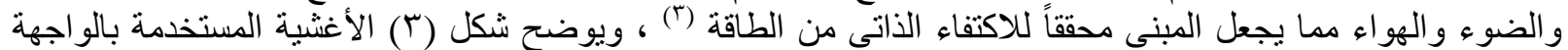

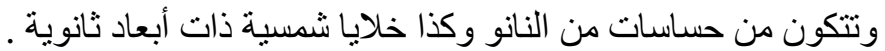
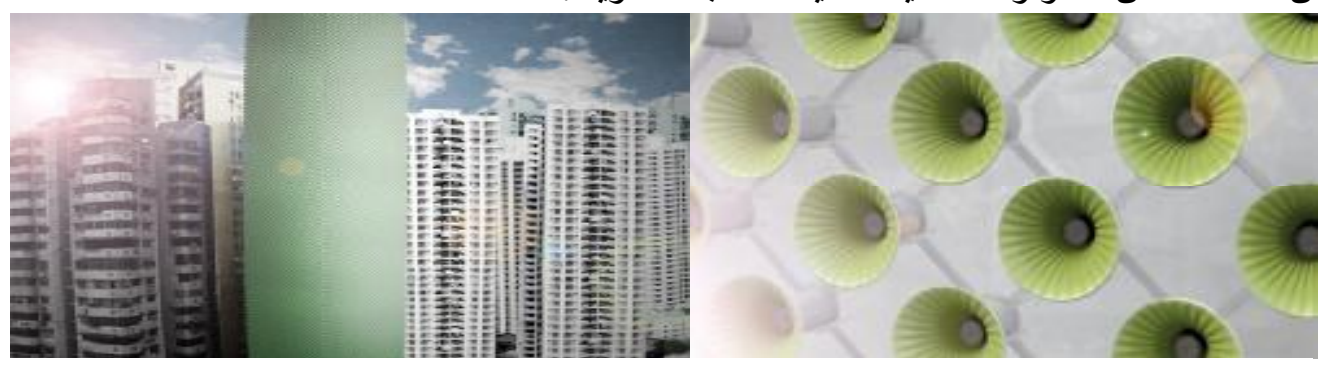

شكل (r) يوضح الاغشية المستخدمة بالواجهة والناقلة لعناصر المياه والهواء والضوء المرجع : ( ؛)

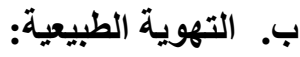

تتفاعل الأغشية الموجدة بالواجهة ، عن طريق توجيه الهواء و الرياح من خلال واجهة المبنى ليتم تنقيته وتوفير الهواء النقي
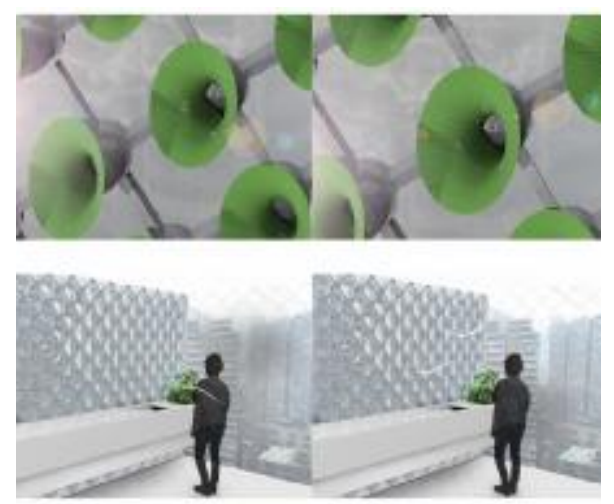

شكل (؛) ) يوضح الاغشية المستخدمة لنقل

الهواء المرجع : (4) (1) (1)

شكل (0) يوضح الاغشية المستخدمة وإعادة تدوير

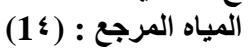

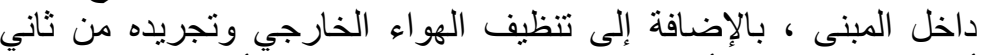

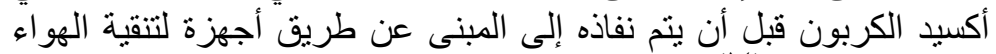

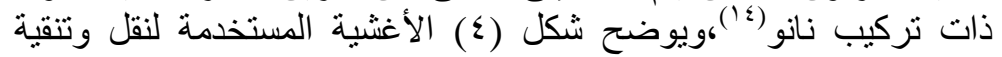
الهو اء. ت ترفير

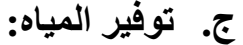

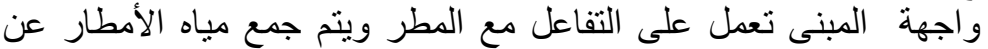

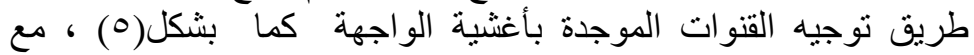

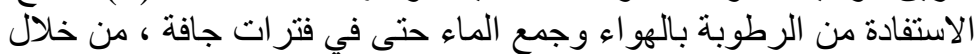

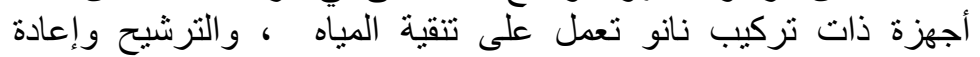

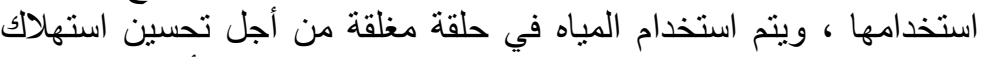

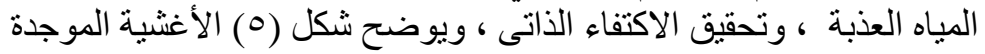
بالو اجهات لإعادة تدوير المياه.

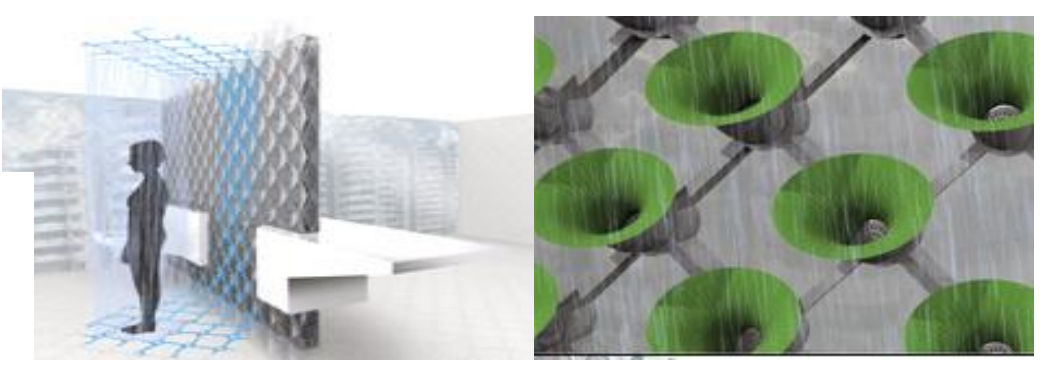


د. إعادة التدوير النفايات الموجدة بالمبنى:

يتم تحويل النفايات البشرية والنفايات العضوية الأخرى إلى طاقة الغاز الحيوي ، ويمكن استخدام الغاز الحيوي للتدفئة
\end{abstract} و الطبخ وكذلك توفير الماء الساخن ،كما بشكل (7) ).

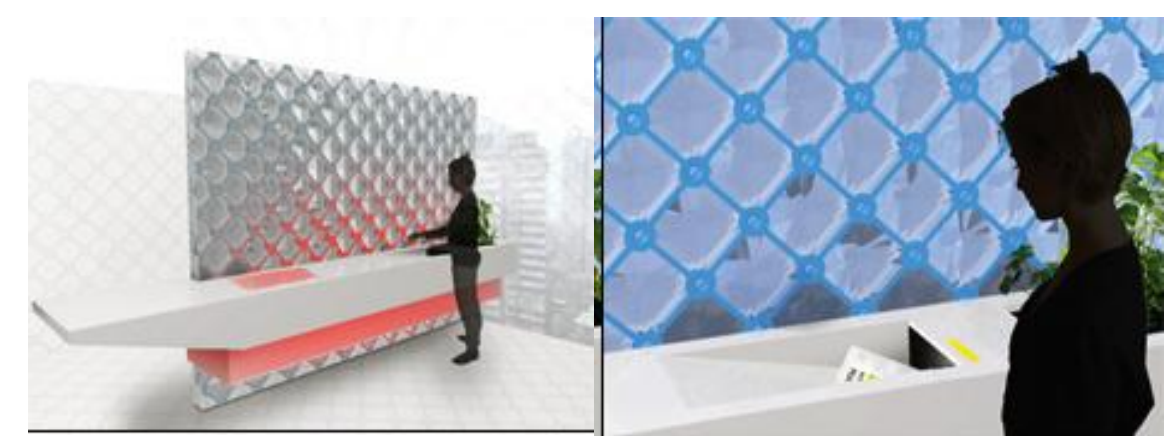

شكل (†) يوضح الاغثية المستخدمة وإعادة تدوير النفايات البشرية والعضوية المرجع : ( V )

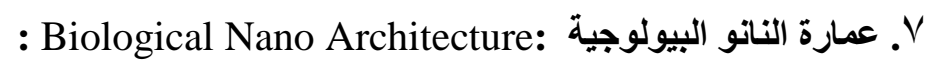

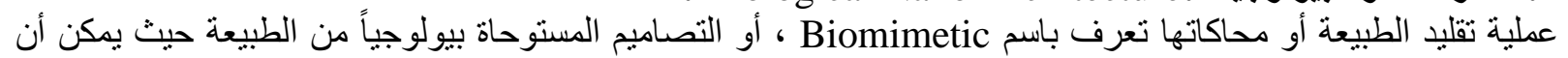

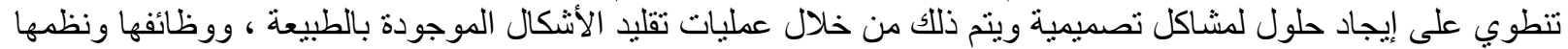

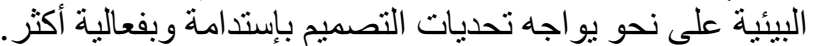

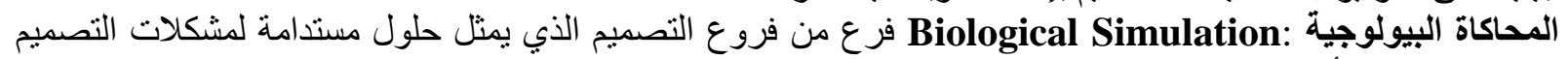

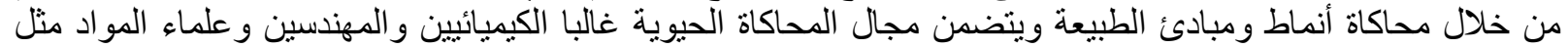

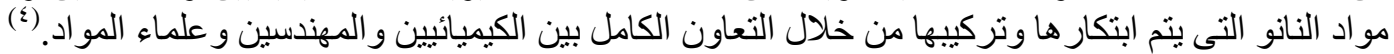

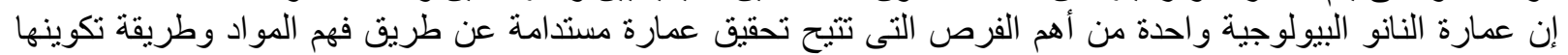

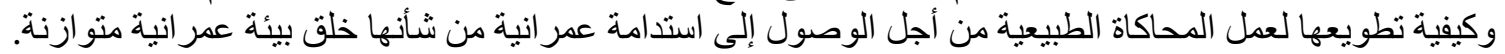

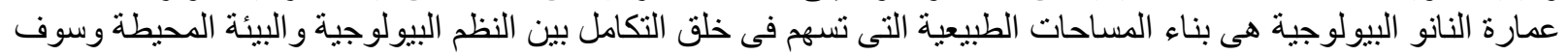

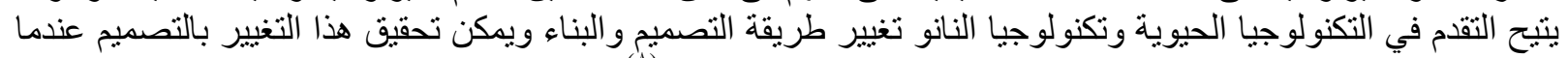

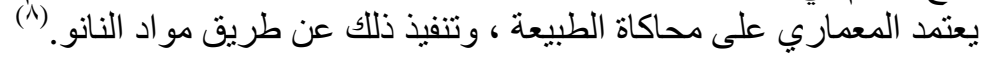

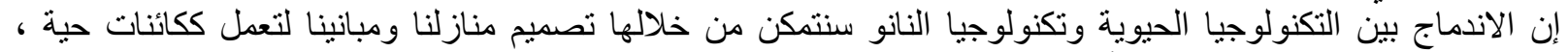

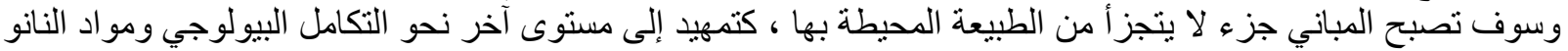
، للعمل على حل العديد من قضايا استدامة العمارة.

Farah Farah, Moti Bodek and تصميم The Breathing Building من أمثلة عمارة النانو البيولوجية مبنى

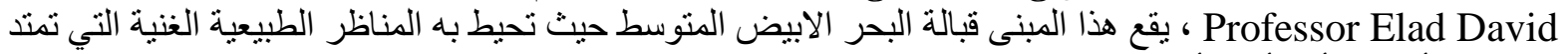
بين مدينة أثندود (أحد أهم و أكبر المدن الفلسطينية المحتلة) في الجنوب الإبن وميناءها الرئيسي في الثمال 


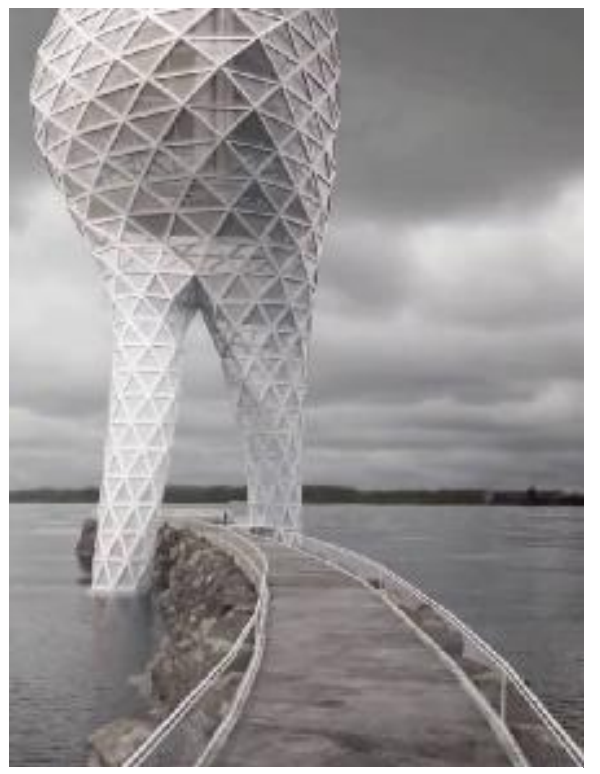

شكل (v) مبنى The Breathing

\section{The Breathing Building}

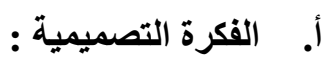

أجرت جامعة ييل Yale University بحثًا بارزًا ، بالاعتماد على أنماط

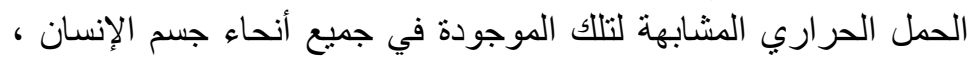
تقترح أنظمة للتهوية التي يتم التحكم فيها وتتألف من أعمدة ديناميكية تعمل التهاء

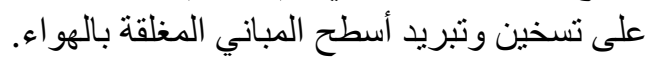
اقترح المهندس المعماري دوريس سونغ تكييف البيئات الداخلية باستخدام

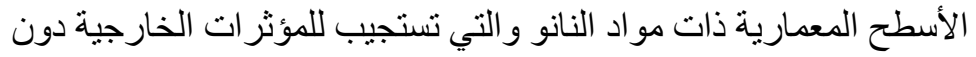
استهلاك موارد الطاقة الخارجية. تم بناء المبنى الرئيسي فوق مستوى سطح البحر عن طأنة طريق دعامتين

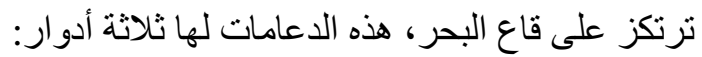

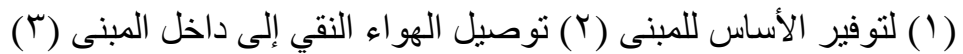
ضخ المياه للمبنى بصوره طبيعية.

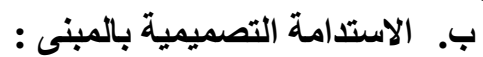

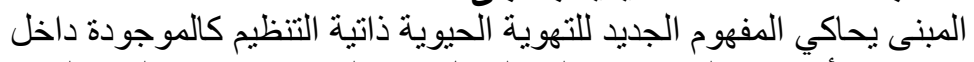

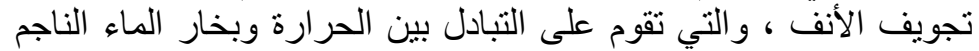

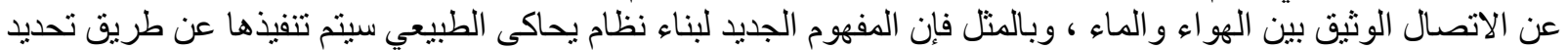

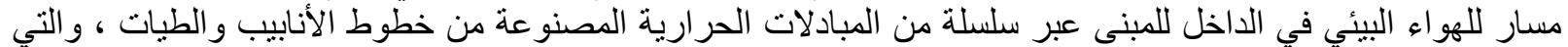

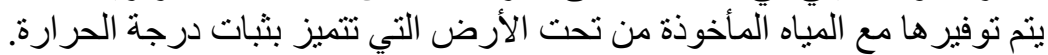

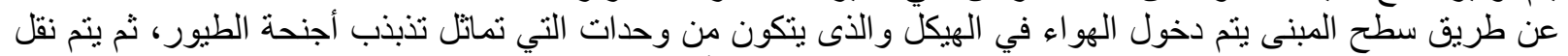

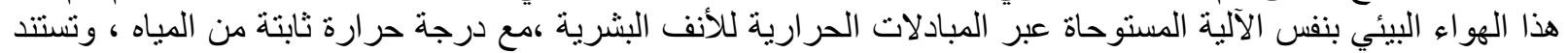

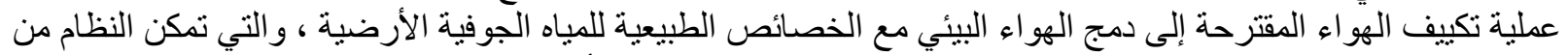

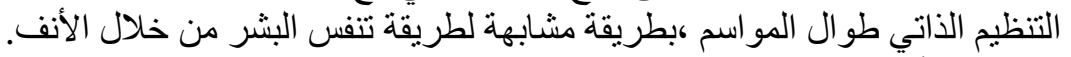
ج. تأثير النانو بالمبنى:

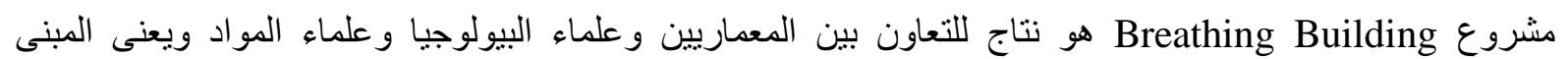

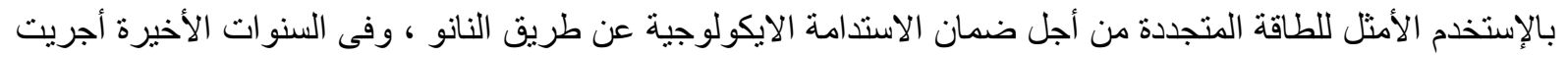

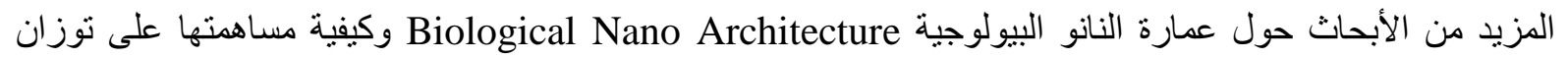

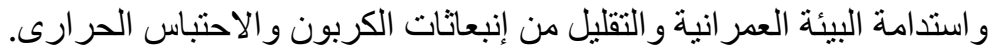

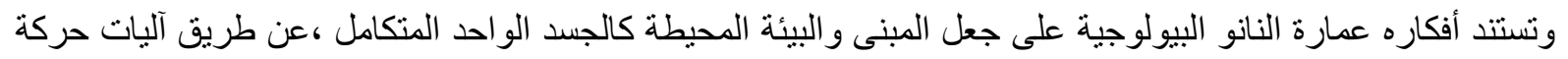

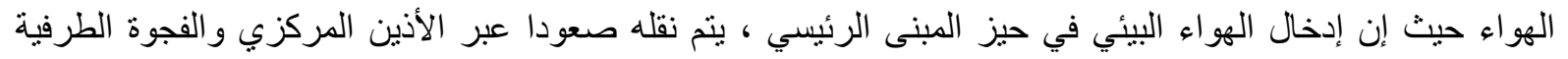

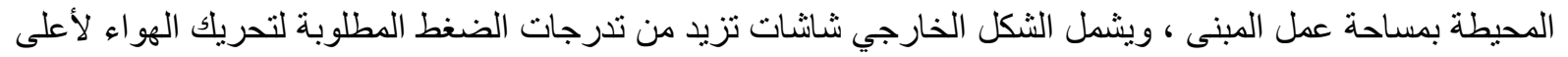
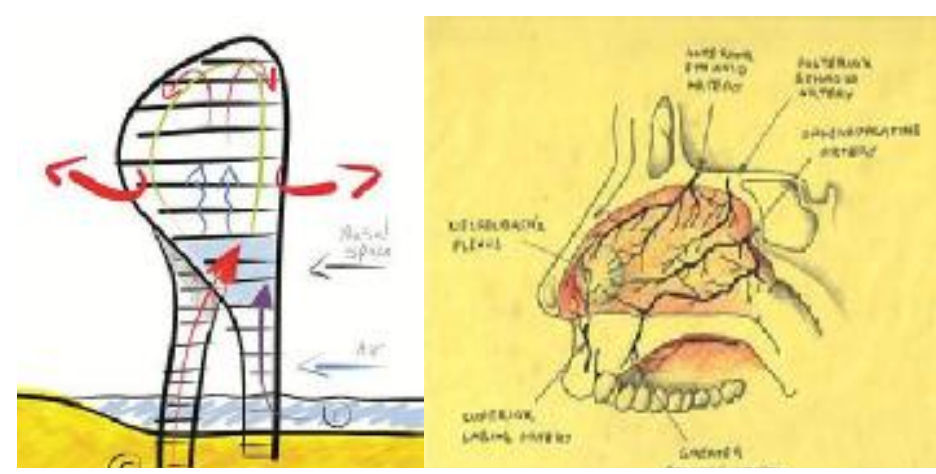

شكل (^) العلاقة الفكرية بين المبنى والفكرة التشريحة للأنف المرجع (11)

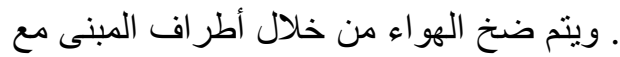

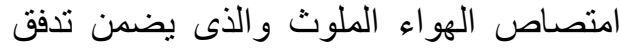

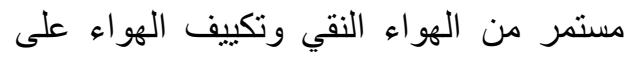
مدار السنة ، (^) يوضح الفكرة التصميمة للمبنى.

A. عمارة النانو الأكية لمانية :Architecture يتحقق التنسيق بين نظم إدارة المبنى الذكي ، وبين

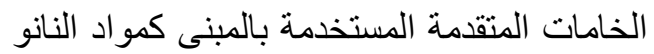
حيث إن هذا التنسيق يدعم منظومة المبنى الذكي 
بالكامل سواء في نواحي توفير الطاقة أو رد الفعل التلقائي تجاه مدخلات البيئة من خلال ما توفره هذه التقنيات من إمكانيات

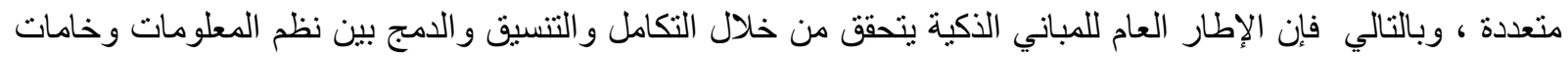
و عناصر البناء الذكية ويوضح شكل (9) النطاق الذي تسنخدم فيه المواد النانوية بالنسبة لنظم ومستويات التنغيل الآلي

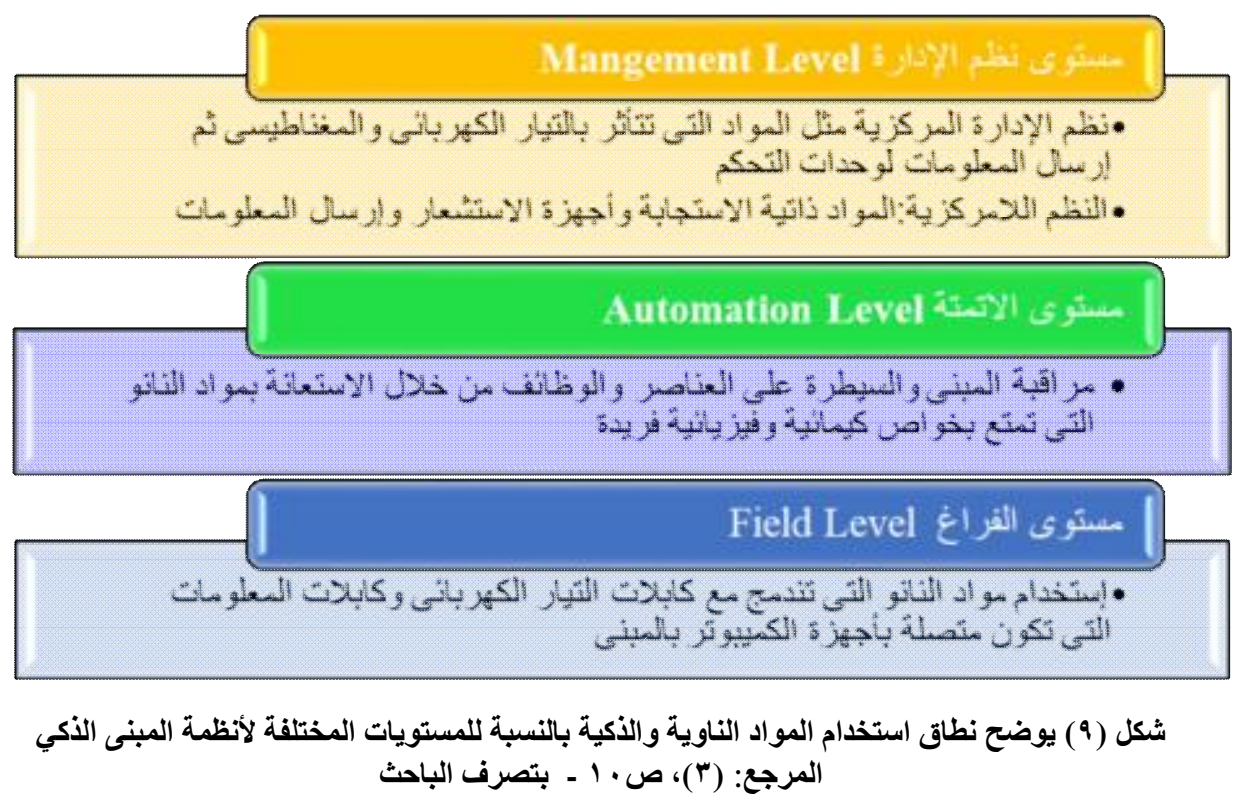

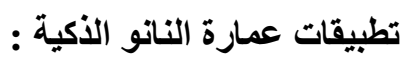

Ara Pacis Museum, Rome, Italy 1

المعمارى: Richard Meier \& Partners

المالك: Comune di Roma, Rome, Italy

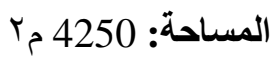

مواد النانو المستخدمة:Lotusan

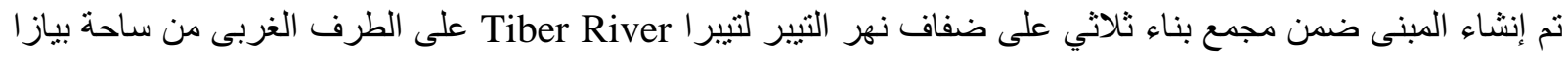

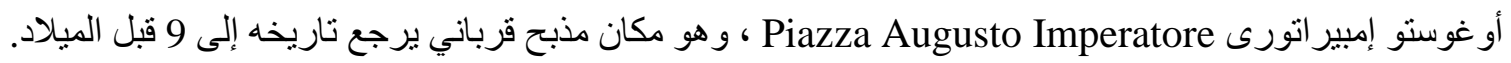

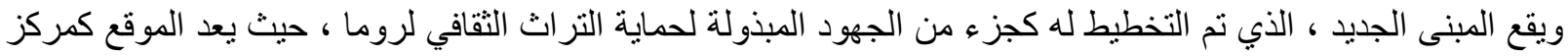

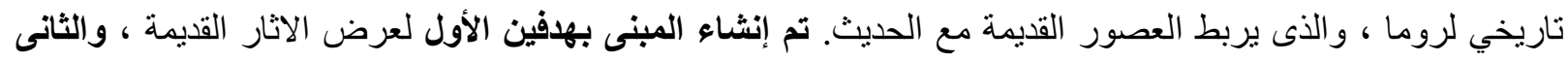
مساحات ومعرض تحتوى على الفن الحديث وقاعات المؤتمرات و المطاعم بالإضافة إلى مناطق أخرى تعد كمساحة

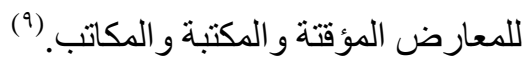
ويمثل المبنى نقطة الالتقاء ما بين الماضى والئن والحاضر و المستقبل حيث إنشاء المبنى يجسد الحضارة الرومانية القديمة مع دمج الاحتياجات الترفيهية الحديثة كقاعات المؤتمر ات و المطاعم فضلا عن مو اد النانو الذكية تم إستخدامها كطلاء ذاتي التنظيف"

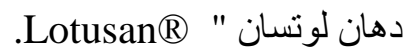

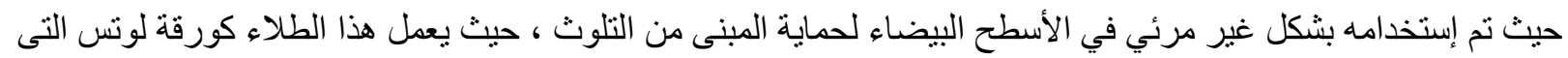

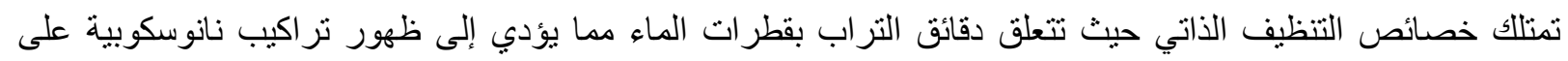
السطح، والذي يؤدي إلى إضعاف التصاق القطرة إلى هذا السطح و هى التقنية التى يعمل بها دهان لوتسان ("')، وفيما يلى لئى

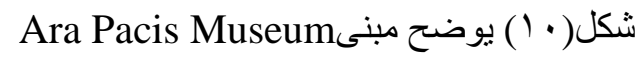




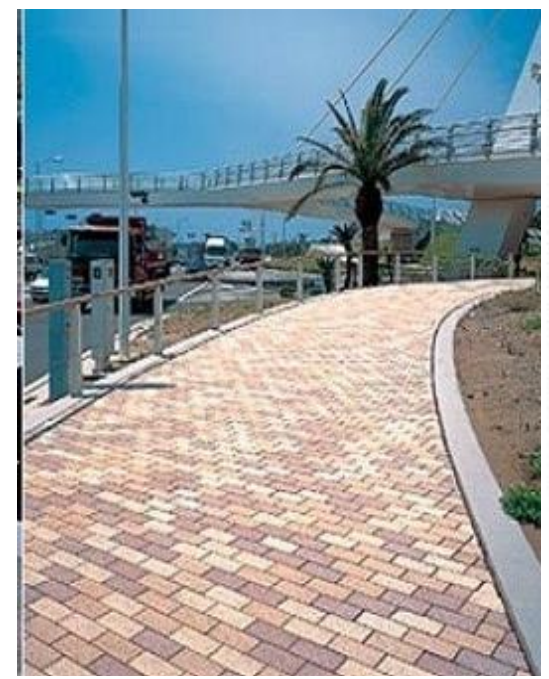

شكل (r ا ) ممرات المشاه وإلمستخدم بها تقتيه التحفيز الضوئى

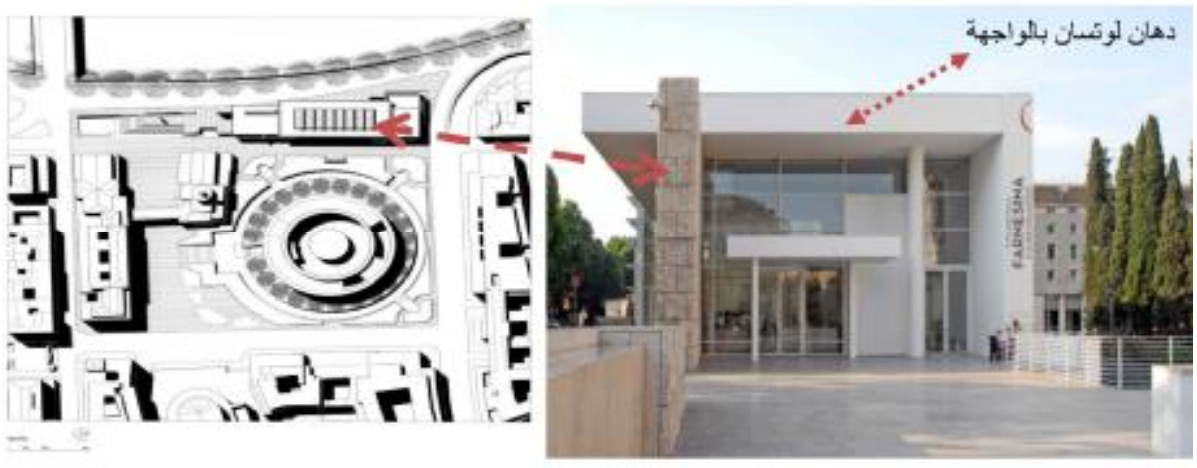

شكل (1 11 ) يوضح شكل مبنى Ara Pacis Museum ومعالجات مواد النانو بواجهته

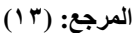

\section{Duisburg, Germany MSV Arena soccer stadium-r مبنى}

AR.TE.plan, Burkhard Grimm, Michael Stehle المعمارى:

المالك: MSV Duisburg

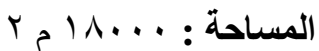

Pilkington Activ, : مواد النانو المستخدمة: المشونة

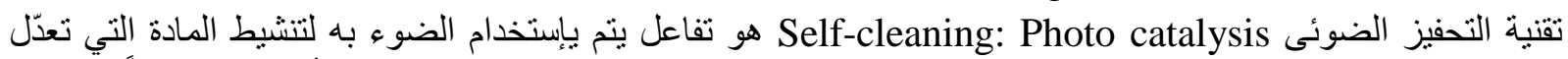

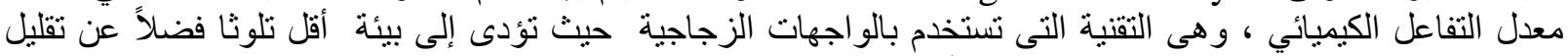

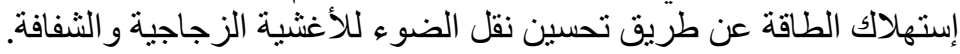

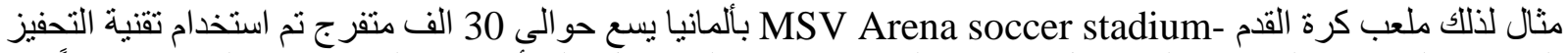

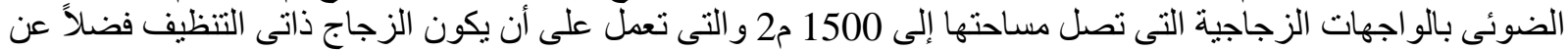

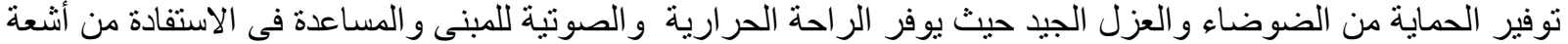

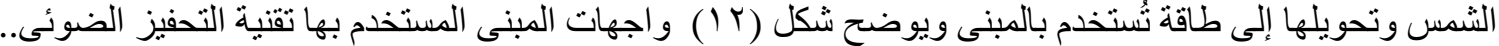

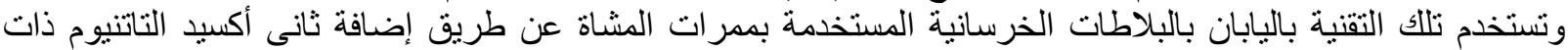

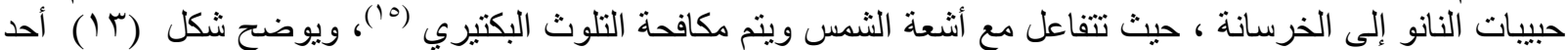

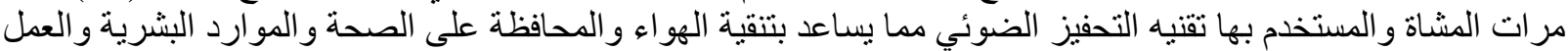
على تحقيق استدامة+ شاملة نحو بيئة عمر انية أفضل النّل

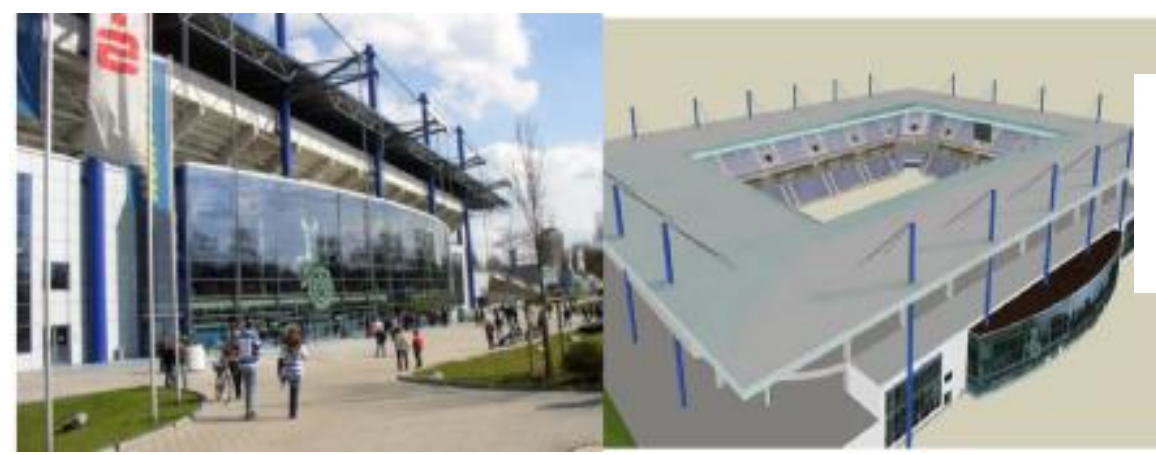

MSV Arena شكل (12) إستاد soccer stadium والمستخدم به تقنية التحفيز الضوئى بواجهته الزجاجية

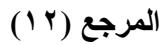




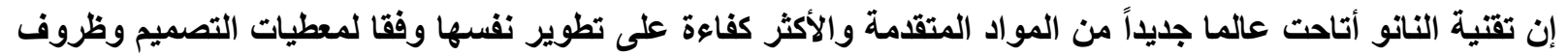

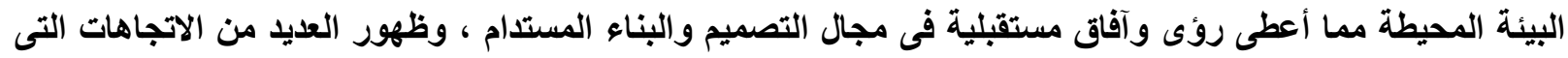

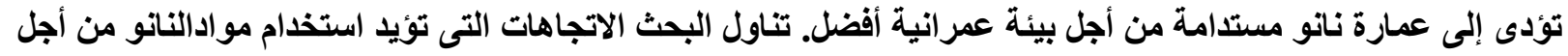

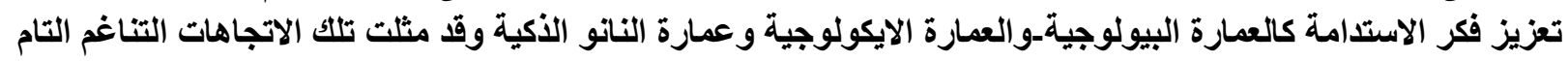

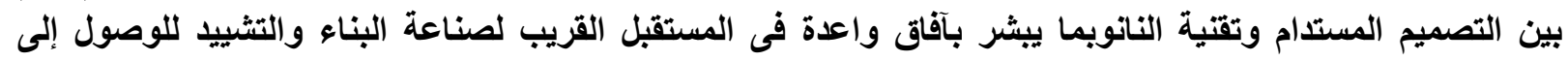

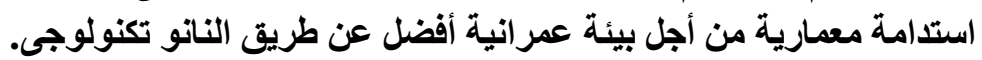

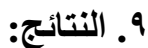

ا. عمارة النانو المستدامة خلقت تناغم بين البيئة الطبيعية والمبنية عن طريق تحقيق الاستدامة وحل المشاكل البيئية

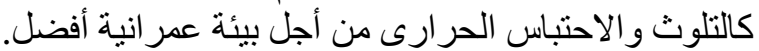

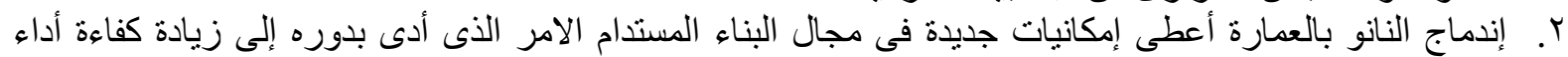

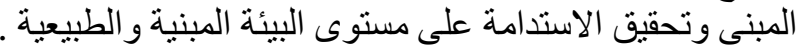

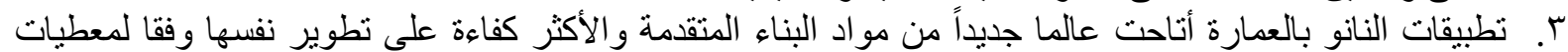

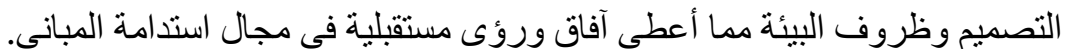

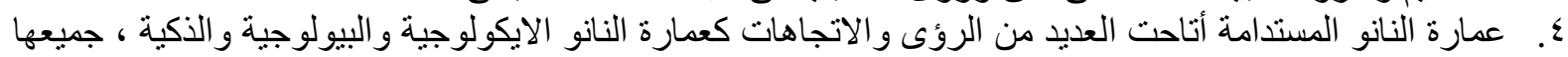

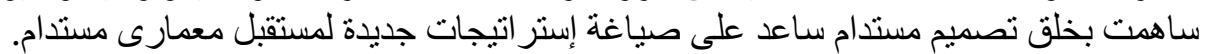

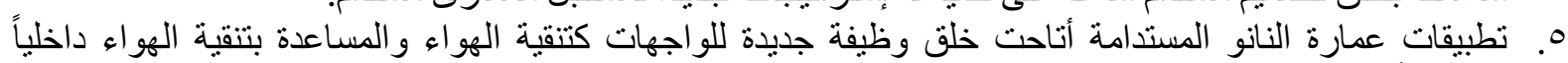

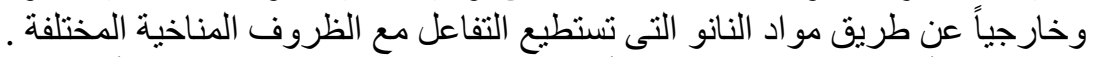

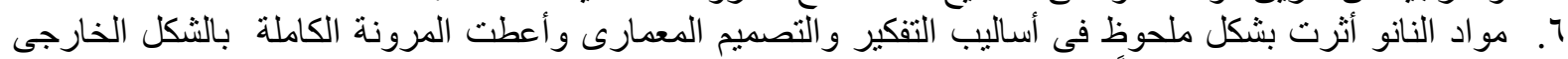

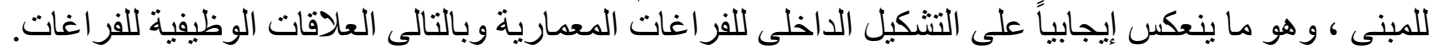

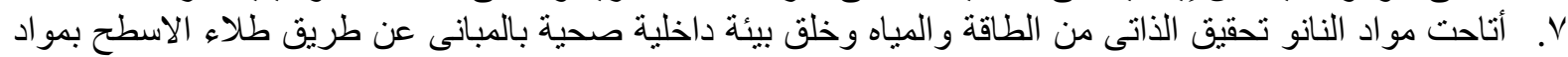

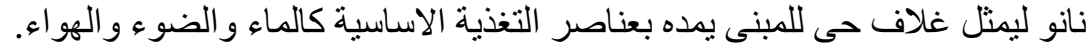

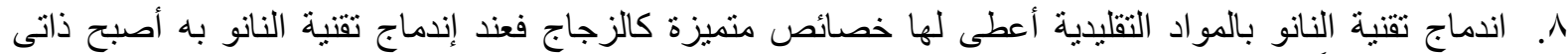

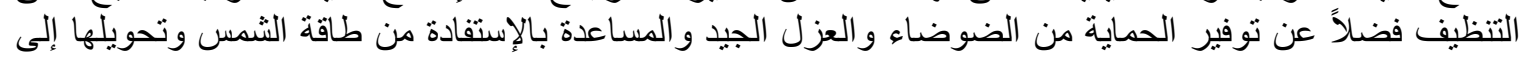

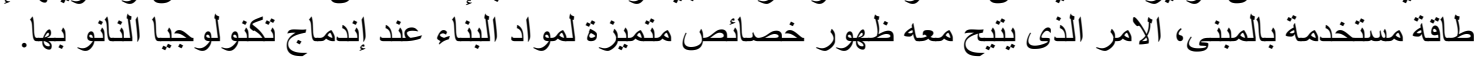

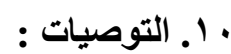
ا ـ يوصى البحث جهات صدُناع القرار بضرورة وضع إطار عام لتحقيق استدامة شاملة عن طريق أدوات تكنولوجية

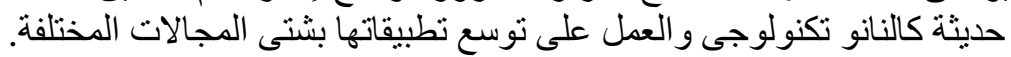

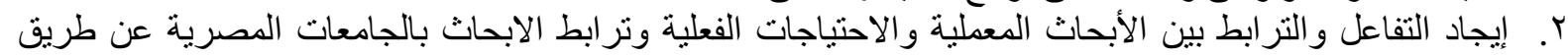

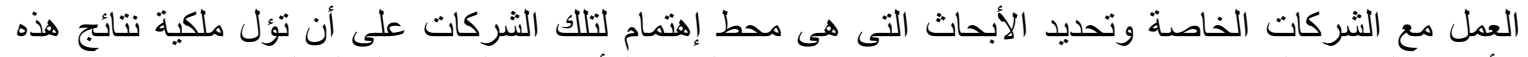
الأبحاث إلى هذه الثركات مستقبلا مما بضمن توفير الاعنماد المادي للأبحاث و التطبيق العملى لها.

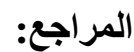

أولا :المراجع العربية

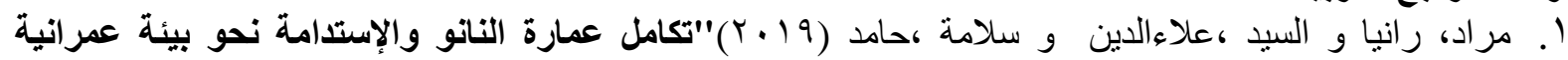

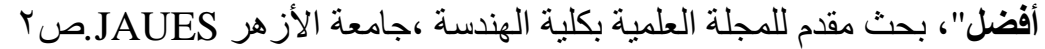

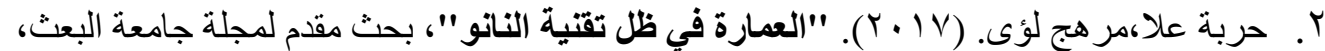

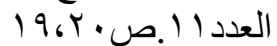

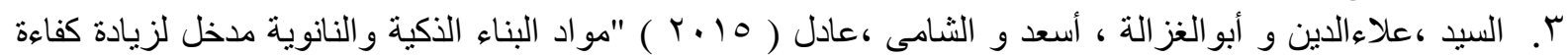

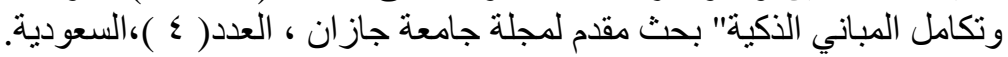

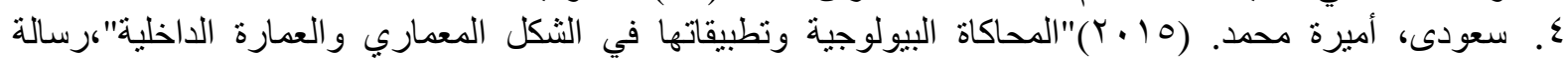

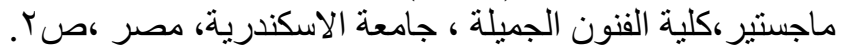

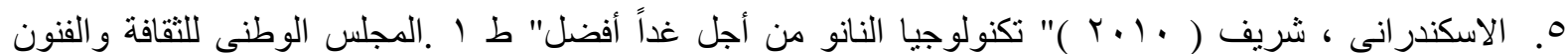




$$
\begin{aligned}
& \text { تكنولوجيا النانو : نحو استدامة معمارية معاصرة }
\end{aligned}
$$

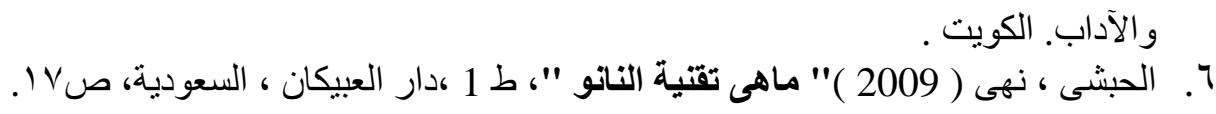

$$
\begin{aligned}
& \text { ثانياً :المراجع الأجنبية }
\end{aligned}
$$

7. Mohamed, A. S. Y. (2015). Nano-Innovation in Construction, A New Era of Sustainability. In International Conference on Environment and Civil Engineering (pp. 95-114). Pattaya, Thailand: ICEACE.

8. Elsamny, M. (2013). Biological NanoArchitecture: Architecture in the Age of Biomaterials. In Advanced Materials Research (Vol. 671, pp. 2174-2179). Trans Tech Publications.

9. Daveiga, J., \& Ferreira, P. (2005). Smart and nano materials in architecture.

10. Technology, K. A. C. f. S. a. (2002)" Strategic Priorities for Energy Technology Program" Retrieved from Kingdom of Saudi Arabia:

11. The Breathing (2016) https://worldarchitecture.org

ثالثاً : مواقع شبكة المعلومات الدولة

12. Schauinsland-Reisen-Arena (MSV Arena)(2014) http://stadiumdb.com

13. Ara Pacis Museum, Rome, Italy (2013) https://www.mastteam.it

14. Off the Grid: Sustainable Habitat 2020 (2008) https://www.yatzer.com/

15. (2006) https://www.concretedecor.net

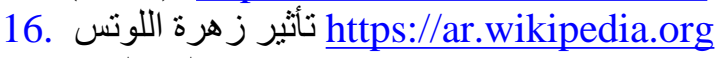

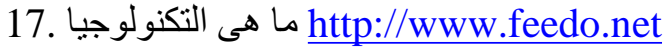

